\title{
Sistem Pendeteksi Kebakaran Menggunakan Raspberry Pi Berbasis Android
}

\author{
I Wayan Pande Agustiana Putra, I Nyoman Piarsa, Kadek Suar Wibawa \\ Program Studi Teknologi Informasi, Fakultas Teknik,Universitas Udayana \\ Bukit Jimbaran, Bali, Indonesia, telp. (0361)701806 \\ e-mail: pandeagustianaputra8@gmail.com, manpits@unud.ac.id, suar wibawa@yahoo.com
}

\begin{abstract}
Abstrak
Kebakaran adalah salah satu bencana yang sering terjadi di masyarakat dapat mengakibatkan kerugian yang cukup besar jika tidak ditangani dengan cepat. Kasus kebakaran yang sering terjadi menyebabkan dibutuhkan adanya sistem yang mampu mendeteksi adanya kebakaran dan memberikan informasi kepada pengguna dari jarak jauh untuk mengurangi dampak dari kebakaran. Teknologi yang dapat digunakan adalah teknologi Internet of Things yang merupakan sebuah teknologi yang memungkinkan benda fisik untuk saling berkomunikasi melalui internet. Sistem pendeteksi kebakaran ini menggunakan tiga sensor yang berfungsi untuk mendeteksi adanya api, asap, dan suhu, serta menggunakan Raspberry Pi sebagai mikrokontroler yang berfungsi untuk memproses data masukan dari sensor. Hasil pengujian menunjukkan bahwa sistem mampu memberikan informasi melalui aplikasi Android jika terdeteksi adanya api, asap kebakaran, dan suhu ruangan yang cukup tinggi. Sistem juga melakukan pencegahan awal kebakaran dengan memutuskan aliran listrik dan menyemprotkan air ke sumber api.
\end{abstract}

Kata kunci: Internet of Things, Deteksi Kebakaran, Raspberry Pi, Mikrokontroller, Android.

Abstract
Fire is one of the most frequent disasters in the society which can cause a serious problem if it is not handled quickly. Fire cases that occur cause the need for a system that is able to detect a fire and provide information to users from a distance to reduce the impact of a fire. The technology that can be used is Internet of Things technology which is a technology that allows physical objects to communicate with each other using Internet connection. This fire detection system uses three sensors that function to detect the presence of fire, smoke, and temperature, and use Raspberry $\mathrm{Pi}$ as a micro controller that functions to process the data from the sensors. The results show that the system is able to provide information through an Android application if there is a high fire, smoke, and room temperature are detected. The system also makes early prevention of fires by disconnect the electricity and spraying water into the fire source.

Keywords : Internet of Things, Fire Detection, Raspberry Pi, Microcontroller, Android.

\section{Pendahuluan}

Kebakaran adalah salah satu bencana yang sering terjadi di masyarakat dan dapat mengakibatkan kerugian yang cukup besar. Kebakaran dapat meluas dan membesar apabila tidak ditangani dengan cepat. Kebakaran dapat terjadi karena adanya beberapa faktor, salah satunya adalah hubungan pendek arus listrik yang sering terjadi [1].

Berdasarkan data yang diperoleh dari Badan Penanggulangan Bencana Daerah Provinsi DKI Jakarta, kejadian kebakaran pada tahun 2013 di Jakarta tercatat sebanyak 541 kasus, sedangkan pada tahun 2014 kejadian kebakaran tercatat sebanyak 696 kasus [2]. Bencana non alam yang paling sering terjadi di Indonesia menurut Pusat Krisis Kesehatan Kementerian Kesehatan RI pada Tahun 2016 salah satunya adalah kebakaran dengan persentase sebesar 20\% [3]. Data tersebut menunjukkan bahwa kebakaran merupakan bencana non alam yang cukup serius dan dibutuhkan adanya penanganan yang tepat.

Kasus kebakaran yang sering terjadi menyebabkan dibutuhkan adanya sistem yang mampu mendeteksi adanya kebakarakan dan memberikan informasi kepada pengguna dari 
jarak jauh. Teknologi yang dapat digunakan adalah Internet of Things yang merupakan sebuah teknologi yang memungkinkan perangkat atau benda fisik untuk saling berkomunikasi melalui internet.

Penelitian yang berkaitan dengan sistem pendeteksi kebakaran berbasis Internet of Things sudah pernah dilakukan sebelumnya. Penelitian yang berjudul Fire Detection System with GSM Using Arduino membuat sebuah sistem pendeteksi kebakaran menggunakan Arduino dan GSM. Sistem akan memberikan notifikasi berupa SMS ketika sensor MQ-5 mendeteksi adanya kebocoran gas [4]. Penelitian kedua dengan judul Rancang Bangun Sistem Pendeteksi Kebakaran Berbasis IoT dan SMS Gateway Menggunakan Arduino. Sistem yang dibuat merupakan sistem pendeteksi kebakaran hutan. Sistem yang dibuat menggunakan Arduino sebagai mikrokontroller serta sensor api, suhu, dan asap. Sistem akan memberikan informasi melalui aplikasi web dan juga SMS [5], namun kedua penelitian tersebut memiliki kelemahan yaitu informasi yang disampaikan masih dalam bentuk SMS. Penelitian yang berkaitan dengan mikrokontroller juga pernah dibuat sebelumnya yang berjudul Perancangan Sistem Informasi Parkir dengan WiFi Berbasis Arduino dimana sistem yang dibuat adalah sistem informasi parkir yang memanfaatkan mikrokontroller Arduino untuk mengetahui ketersediaan parkir melalui aplikasi secara langsung [6] dan penelitian yang berjudul Secure Data Monitoring System with Encrypt Data Transmission over Radio Communication Based on Microcontroller dimana sistem yang dibuat adalah sistem monitoring dengan menggunakan mikrokontroler ATMega32 [7]. Penelitian yang menggunakan Raspberry Pi juga sudah pernah dilakukan sebelumnya yang berjudul Library System Using Radio Frequency Identification (RFID) and Telegram Bot API dimana sistem yang dibuat adalah sistem informasi perpustakaan dengan menggunakan RFID. Raspberry $\mathrm{Pi}$ digunakan untuk menghubungkan RFID dengan sistem untuk melakukan manajemen peminjaman atau pengembalian buku [8].

Berdasarkan penelitian yang dilakukan sebelumnya dibuat sistem pendeteksi kebakaran menggunakan Raspberry Pi berbasis Android yang merupakan sebuah sistem yang mampu mendeteksi kebakaran, melakukan pencegahan awal terjadinya kebakaran, serta memberikan informasi terdeteksi kebakaran kepada pengguna melalui aplikasi Android. Teknologi Internet of Things digunakan pada saat memberikan informasi melalui aplikasi Android.

\section{Metodologi Penelitian}

\subsection{Gambaran Umum Sistem}

Secara umum penelitian sistem pendeteksi kebakaran menggunakan Raspberry $\mathrm{Pi}$ berbasis Android dapat digambarkan seperti pada Gambar 2.



Gambar 1. Gambaran Umum Sistem

Sistem yang dirancang terdiri dari beberapa komponen, yaitu Raspberry Pi 3 B, sensor api, sensor gas, sensor suhu, relay, pompa air, dan kamera. Raspberry Pi 3 B merupakan mikrokontroler yang berfungsi sebagai pusat pengolahan data untuk memproses data yang diberikan oleh sensor-sensor yang digunakan. Sensor-sensor akan mengirim data ke mikrokontroler dan diproses, dimana ketika sensor mendeteksi adanya api, disertai dengan kandungan asap yang tinggi, dan suhu ruangan yang cukup tinggi, maka sistem mendeteksi adanya kebakaran.

Sistem akan memutuskan aliran listrik dan menghidupkan pompa air secara otomatis saat terdeteksi kebakaran sebagai pencegahan awal terjadinya kebakaran sehingga meminimalisir terjadinya kebakaran yang lebih besar. Sistem juga memberikan informasi 
terdeteksi kebakaran kepada pengguna melalui aplikasi Android. Pengguna juga dapat melakukan controlling dan monitoring melalui aplikasi berbasis Android seperti yang ditunjukkan pada Gambar 1. Pengguna dapat melakukan kontrol listrik, yaitu menghidupkan dan memutuskan aliran listrik serta memantau suhu ruangan.

\subsection{Perancangan Rangkaian Alat}

Perancangan rangkaian alat merupakan perancangan yang untuk menghubungkan Raspberry Pi dengan perangkat keras lainnya seperti sensor api, sensor suhu, sensor gas, relay, dan buzzer.

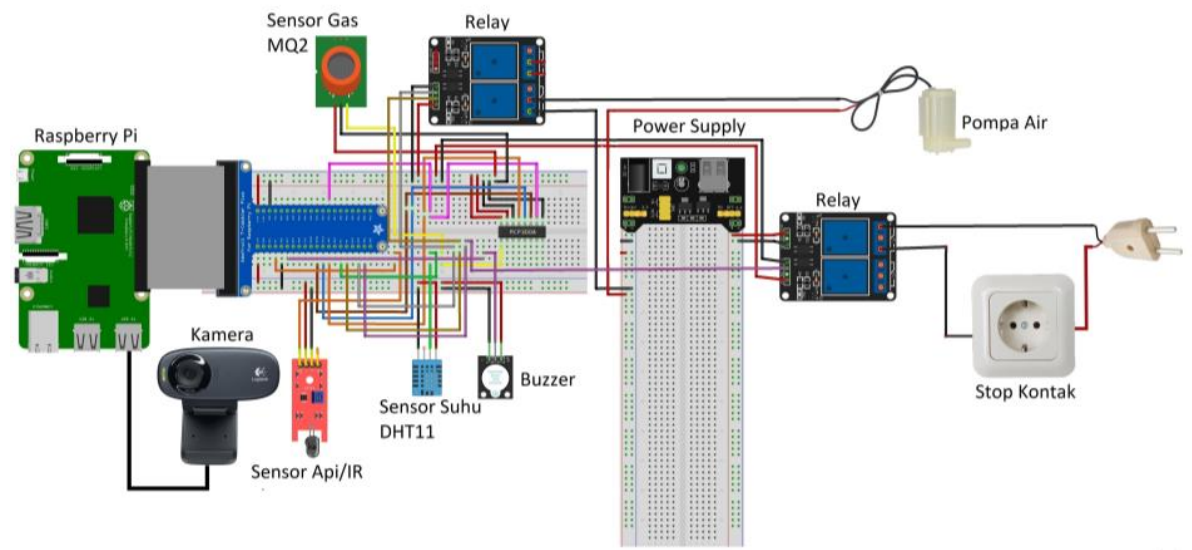

Gambar 2. Perancangan Rangkaian Alat

Raspberry Pi dihubungkan dengan sensor api melalui 3 port yang dimiliki sensor api yaitu VCC, GND, dan DO seperti yang ditunjukkan pada Gambar 2. Raspberry Pi dihubungkan dengan sensor suhu melalui 3 port yang dimiliki sensor suhu yaitu VCC, GND, dan DO. Raspberry Pi dihubungkan dengan sensor gas melalui 3 port yaitu VCC, GND, dan AO, serta menggunakan ADC MCP3008 yang berfungsi untuk mendapatkan keluaran berupa nilai analog dari sensor gas. Raspberry Pi dihubungkan dengan buzzer melalui 3 port yaitu VCC, GND, dan I/O. Raspberry Pi dihubungkan dengan pompa air dan listrik menggunakan relay agar dapat bekerja sesuai dengan perintah yang diberikan dari Raspberry Pi ke relay. Raspberry Pi dihubungkan dengan kamera melalui kabel usb port yang ada pada Raspberry Pi.

\section{Kajian Pustaka}

Kajian pustaka memuat materi yang menjadi referensi penelitian ini. Referensi yang dimuat yaitu, Internet of Things, Raspberry Pi, Sensor IR Flame, Sensor Gas MQ2, Sensor Suhu dan Kelembaban DHT11.

\subsection{Internet of Things}

Internet of Things merupakan sebuah teknologi yang menggunakan internet untuk melakukan controlling dan komunikasi dengan berbagai perangkat lainnya. Internet of Things merupakan bentuk perubahan dan perkembangan teknologi informasi serta jaringan internet, sehingga perangkat elektronik dapat dengan mudah terhubung melalui internet dan internet mampu memenuhi kebutuhan akan pengalamatan dan konektivitas [9]. Internet of Things juga dapat didefinisikan sebagai suatu paradigma di mana objek yang dilengkapi dengan sensor dan perangkat keras lainnya saling berkomunikasi satu sama lain dengan tujuan tertentu [10].

\subsection{Raspberry Pi}

Raspberry Pi dirilis pertama kali pada bulan Februari tahun 2012 dan dikembangkan oleh yayasan nirlaba Raspberry Pi Foundation dan ahli komputer dari Universitas Cambridge, Inggris dan merupakan salah satu Single Board Computer (SBC) [11]. Raspberry Pi merupakan sebuah mikrokontroler yang memiliki ukuran sebesar kartu kredit yang dapat bekerja seperti komputer ketika dihubungkan dengan monitor, keyboard, dan mouse [12]. Raspberry Pi yang digunakan dalam pembuatan sistem adalah Raspberry Pi 3B. Raspberry Pi 3B memiliki spesifikasi processor Broadcom quad-core 1.2GHz, RAM 1GB, wireless LAN dan Bluetooth, 
40pin GPIO. Raspberry Pi berfungsi sebagai pusat pengolahan data dari masukan sensorsensor yang digunakan.

\subsection{Sensor IR Flame}

Sensor IR Flame merupakan sebuah sensor berbasiskan inframerah yang berfungsi untuk mendeteksi keberadaan api. Sensor IR Flame bekerja berdasarkan inframerah dimana sensor mampu mendeteksi api atau sumber cahaya dengan jarak deteksi kurang dari 1 meter dan rentang panjang gelombang 760nm hingga 1100nm. Sensor IR Flame memiliki 3 pin, yaitu VCC, GND, dan Digital Output. Sensor IR Flame digunakan sebagai sensor api untuk mendeteksi sumber keberadaan api kebakaran.

\subsection{Sensor Suhu dan Kelembaban DHT11}

Sensor suhu dan kelembaban DHT11 merupakan sebuah sensor yang dapat melakukan pengukuran suhu dan kelembaban udara. Sensor DHT11 digunakan sebagai pendeteksi suhu sehingga dapat mengukur suhu ketika terjadi kebakaran.

\subsection{Sensor Gas MQ-2}

Sensor gas MQ-2 merupakan sebuah sensor yang digunakan untuk mendeteksi kandungan gas LPG, i-butana, propana, metana, alkohol, hidrogen, dan asap. Sensor gas MQ2 memiliki 4 pin, yaitu VCC, GND, Analog Output, dan Digital Output. Sensor MQ-2 digunakan untuk mendeteksi kandungan dari asap kebakaran.

\subsection{Android}

Android merupakan salah satu sistem operasi pada perangkat mobile berbasis linux yang terdiri dari sistem operasi, middleware, dan aplikasi. Android merupakan platform yang open source sehingga memudahkan bagi para pengembang untuk membuat suatu aplikasi. Google Inc. membeli Android Inc. dan merupakan pendatang baru dalam pembuatan piranti lunak untuk ponsel pintar [13]. Aplikasi Android dapat dikembangakan menggunakan IDE Android Studio, dimana bahasa pemrograman yang digunakan adalah JAVA. Android merupakan sistem operasi mobile yang semakin populer dan diminati oleh masyarakat umum [14][15].

\section{Hasil dan Pembahasan}

Hasil dan pembahasan sistem pendeteksi kebakaran menggunakan meliputi hasil rancangan alat sistem pendeteksi kebakaran dan uji coba aplikasi Android.

\subsection{Hasil Prototipe}

Prototipe merupakan rangkaian alat untuk mendeteksi kebakaran, dimana dibuat menggunakan papan triplek dengan ukuran $35 \times 25 \times 10 \mathrm{~cm}$ yang berisi rangkaian alat dan sensor yang dapat dilihat pada Gambar 3.

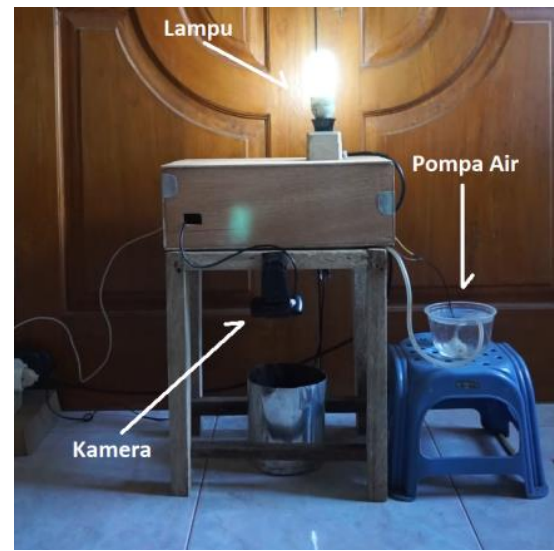

(a)

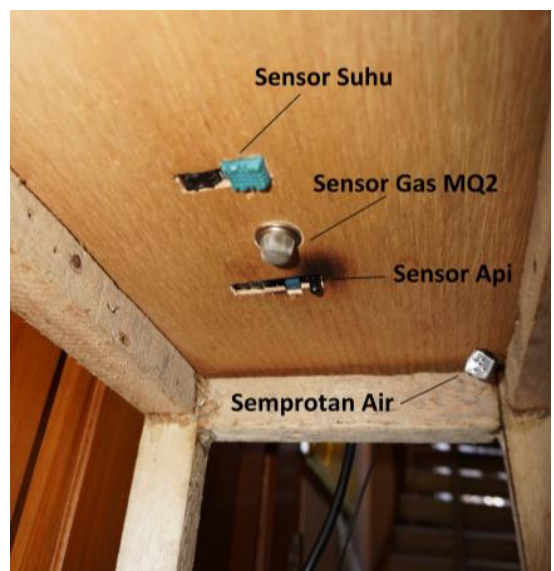

(b)

Gambar 3. (a) Prototipe Keseluruhan (b) Rangkaian Sensor 
Prototipe digunakan untuk melakukan pengujian sistem dalam melakukan deteksi kebakaran, mengirimkan informasi, serta melakukan pencegahan awal terjadinya kebakaran. Rangkaian alat terdiri dari Raspberry Pi, sensor api, sensor suhu, sensor gas, kamera, lampu, dan pompa air seperti yang terlihat pada Gambar 3. Raspberry Pi dan tiga sensor lainnya digunakan untuk membaca kondisi ketika terjadi kebakaran. Kamera berfungsi untuk menangkap gambar ketika sistem mendeteksi adanya kebakaran, api, asap, atau suhu yang tinggi, dan pompa air berfungsi untuk menyemprotkan air ke sumber api ketika terdeteksi adanya kebakaran, sedangkan lampu merupakan simulasi pemutusan aliran listrik suatu ruangan.

\subsection{Pengujian Sistem}

Pengujian dilakukan dengan melakukan simulasi kebakaran menggunakan asap dan api yang bersumber dari pembakaran kertas dan kayu, dimana jarak antara sumber kebakaran dengan rangkaian sensor adalah $25 \mathrm{~cm}$. Pengujian dilakukan untuk mengetahui keberhasilan sistem mendeteksi adanya kebakaran, melakukan pencegahan awal kebakaran, dan memberikan informasi kepada pengguna melalui aplikasi berbasis Android.

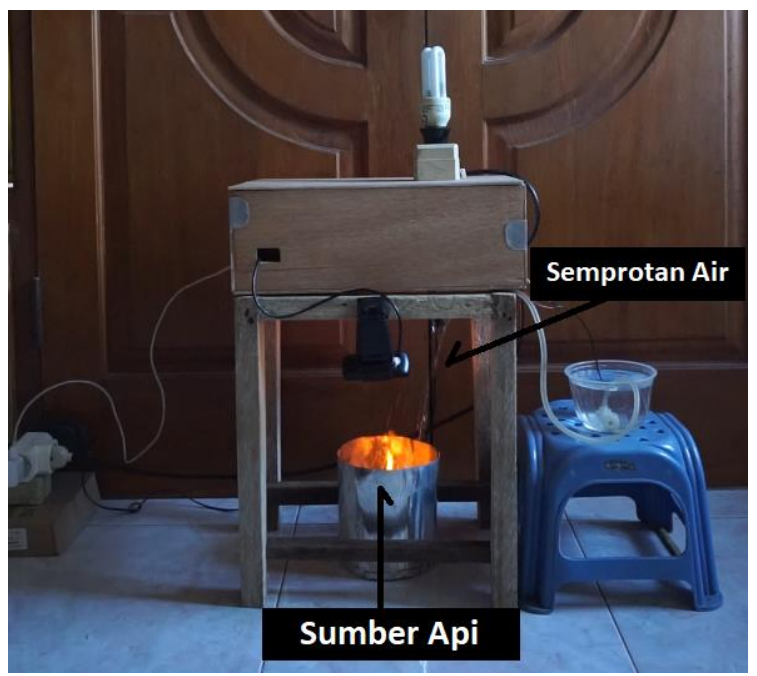

Gambar 4. Pengujian Sistem

Sistem mampu melakukan pencegahan awal kebakaran secara dini dengan menyemprotkan air ke sumber api dan memutuskan aliran listrik yang ditandai dengan padamnya lampu secara otomatis ketika terdeteksi adanya kebakaran seperti yang ditunjukkan pada Gambar 4. Kamera yang dipasangkan pada prototipe alat akan menangkap gambar dan selanjutnya sistem memberikan informasi terdeteksi kebakaran kepada pengguna melalui aplikasi berbasis Android. 




(a)

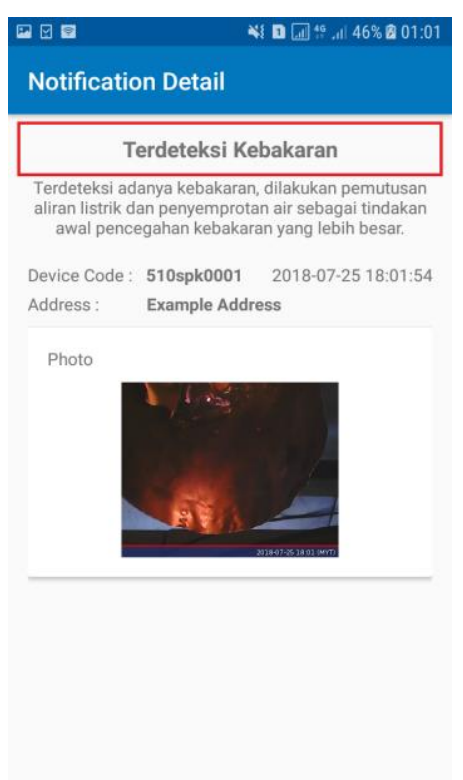

(b)

Gambar 5. (a) Daftar Notifikasi (b) Informasi Detail Terdeteksi Kebakaran

Informasi terdeteksi kebakaran diberikan kepada pengguna dalam bentuk listview yang berisi daftar notifikasi dengan informasi pesan, alamat, dan waktu notifikasi dikirimkan seperti yang ditunjukkan pada Gambar 5. Pengguna juga mendapatkan informasi ketika sistem hanya mendeteksi adanya api, asap, atau suhu yang tinggi. Setiap notifikasi memiliki informasi detail yaitu pesan, kode perangkat, alamat perangkat, waktu notifikasi dikirimkan, dan foto yang ditangkap kamera. Aplikasi juga memiliki fitur untuk melakukan pemantauan suhu ruangan dan melakukan kontrol terhadap aliran listrik. Fitur controlling dan monitoring ini dapat dilakukan dimana saja dan kapan saja menggunakan aplikasi mobile berbasis Android.
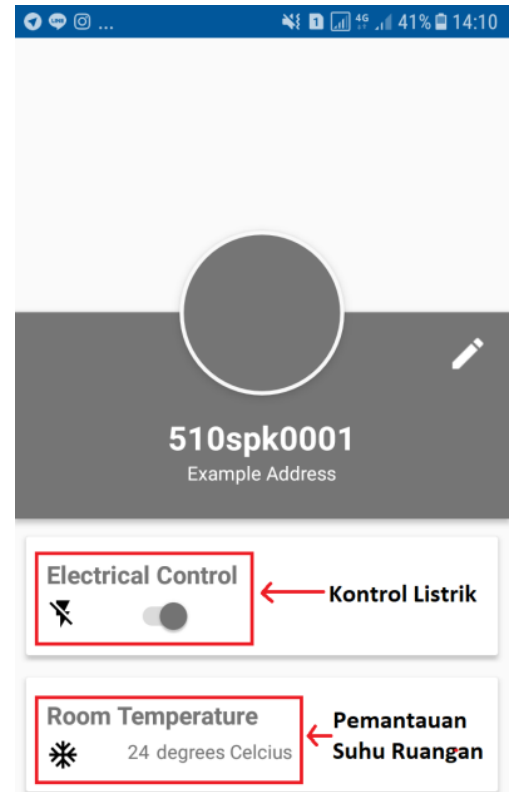

Gambar 6. Fitur Controlling dan Monitoring

Pengguna dapat melakukan controlling aliran listrik yang menuju suatu ruangan melalui aplikasi berbasis Android dengan menggeser switch button yang ada pada halaman detail 
perangkat. Sistem akan mematikan atau menghidupkan lampu ketika pengguna melakukan controlling terhadap aliran listrik. Pengguna juga dapat melakukan monitoring suhu ruangan sehingga dapat mengetahui suhu ruangan secara real-time, seperti yang terlihat pada Gambar 6 suhu ruangan yang terdeteksi oleh sensor adalah 24 derajat celcius.

\section{Kesimpulan}

Sistem pendeteksi kebakaran menggunakan Rapsberry $\mathrm{Pi}$ berbasis Android menggunakan teknologi Internet of Things mampu memberikan informasi melalui aplikasi berbasis Android ketika terdeteksi adanya kebakaran. Sistem juga melakukan penanganan awal terjadinya kebakaran dengan memutuskan aliran listrik dan menyemprotkan air ke sumber api. Fitur lainnya pada aplikasi juga memungkinkan pengguna untuk melakukan controlling aliran listrik dan monitoring suhu ruangan dari jarak jauh.

\section{Daftar Pustaka}

[1] R. S. Rizki, I. D. Sara, M. Gapy, Sistem Deteksi Kebakaran Pada Gedung Berbasis Programmable Logic Controller (PLC), KITEKTRO: Jurnal Online Teknik Elektro, vol. 2 no. 3, pp. 99-104, 2017.

[2] http://data.jakarta.go.id/dataset/data-rekapitulasi-kejadian-kebakaran-di-dki-jakarta, diakses tanggal 12 Agustus 2018.

[3] K. K. R. Indonesia, Profil Kesehatan Indonesia Tahun 2016, Jakarta: Kementerian Kesehatan Republik Indonesia, 2017.

[4] M. S. Sharma, D. Singh, S. S. Rathore, Fire Detection System with GSM Using Arduino, Imperial Journal of Interdisciplinary Research, vol. 3 no. 4, pp. 2243-2245, 2017.

[5] D. Sasmoko, A. Mahendra, Rancang Bangun Sistem Pendeteksi Kebakaran Berbasis loT dan SMS Gateway Menggunakan Arduino, Jurnal Simetris, vol. 8 no. 2, pp. 469-476, 2017.

[6] N. Yuliantoa, F. Bacharuddina, Perancangan Sistem Informasi Parkir dengan WiFi Berbasis Arduino, Lontar Komputer, vol. 7 no. 3, pp. 132-137, 2016.

[7] K. S. Wibawa, I. N. Piarsa, Secure Data Monitoring System with Encrypt Data Transmission over Radio Communication Based on Microcontroller, International Journal of Computer Applications, vol. 179 no. 21, pp. 19-22, 2018.

[8] D. A. K. Arimbawa P, I. K. G. D. Putra, I. M. Sukarsa, Library System Using Radio Frequency Identification(RFID) and Telegram Bot API, Lontar Komputer, vol. 9 no. 1, pp. 40-51, 2018.

[9] I. P. A. E. Pratama, S. Suakanto, Wireless Network Sensor, Bandung: Informatika Bandung, 2015.

[10]P. Sethi, S. R. Sarangi, Internet of Things: Architectures, Protocols, and Applications, Hindawi Journal of Electrical and Computer Engineering, pp. 1-25, 2017.

[11]D. Kurniawan, Membangun Aplikasi Elektronika dengan Raspberry Pi 2 dan Whatsapp, Jakarta: PT Elex Media Komputindo, 2016.

[12] A. A. Basaif, S. A. Aljunid, N. Sabri, M. I. Omer, M. S. Salim, Design and Implementation of an Embedded System to Analysis an Ecg Signal for Heart Diagnosis System, Journal of Theoretical and Applied Information Technology, vol. 91 no. 2, pp. 289-297, 2016.

[13] M. Harmadya, G. M. A. Sasmita, N. K. A. Wirdiani, Rancang Bangun Aplikasi TryoutUjian Nasional Sekolah Menengah Pertama (SMP) Berbasis Android, Lontar Komputer, vol. 6 no. 2, pp. 108-119, 2015.

[14]P. S. Putra, I. K. G. D. Putra, I. N. Piarsa, Aplikasi Peramalan Watak dan Perjodohan Berdasarkan Wariga Bali Berbasis Android dengan Metode Fuzzy Logic, Merpati, vol. 2 no. 3, pp. 380-391, 2014.

[15]A. Rahmi, I. N. Piarsa, P. W. Buana, FinDoctor-Interactive Android Clinic Geographical Information System Using Firebase and Google Maps API, International Journal of New Technology and Research (IJNTR), vol. 3 no. 7, pp. 8-12, 2017. 